Correspondence

Takashi lizuka

takashi_iizuka@ajinomoto.com

\section{Plesiocystis pacifica gen. nov., sp. nov., a marine myxobacterium that contains dihydrogenated menaquinone, isolated from the Pacific coasts of Japan}

\author{
Takashi lizuka, ${ }_{1}^{1}$ Yasuko Jojima, ${ }^{1}$ Ryosuke Fudou, ${ }^{1}$ Akira Hiraishi, ${ }^{2}$ \\ Jong-Woong $A n^{3}$ and Shigeru Yamanaka ${ }^{1,4}$ \\ ${ }^{1}$ Microbiology Group, Institute of Life Sciences, Ajinomoto Co., Inc., 1-1 Suzuki-cho, \\ Kawasaki-ku, Kawasaki, 210-8681, Japan \\ ${ }^{2}$ Department of Ecological Engineering, Toyohashi University of Technology, Tenpaku-cho, \\ Toyohashi, 441-8580, Japan \\ ${ }^{3}$ Medicinal Science Division, Korea Research Institute of Chemical Technology, P. O. Box 107, \\ Yusong, Daejon, 305-600, Korea \\ ${ }^{4}$ Experimental Farm, Faculty of Textile Science and Technology, Shinshu University, Ueda, \\ 386-8567, Japan
}

\begin{abstract}
Two strains of a novel myxobacterium (designated SIR-1 ${ }^{\top}$ and $\mathrm{SHI}-1$ ) were isolated from Japanese coasts located in the Pacific subtropical zone. Cells of both strains were Gram-negative, rodshaped and motile by gliding. The strains were chemoheterotrophic and strictly aerobic. They had the common characteristics associated with myxobacteria, such as bacteriolytic action and fruitingbody formation. The characteristic feature of the strains was a $\mathrm{NaCl}$ growth requirement with an optimum concentration of $2 \cdot 0-3 \cdot 0 \%(\mathrm{w} / \mathrm{v})$, comparable to that of sea water. In addition, other cationic components of sea water, such as $\mathrm{Mg}^{2+}, \mathrm{Ca}^{2+}$ and $\mathrm{K}^{+}$, were needed for growth. The major respiratory quinone was $\mathrm{MK}-8\left(\mathrm{H}_{2}\right)$. The cellular fatty acid profile was characterized by the predominance of iso- $C_{15: 0}$. Characteristic fatty acids anteiso- $C_{16: 0}$ and anteiso- $C_{17: 0}$, and a long-chain polyunsaturated fatty acid $\left(\mathrm{C}_{20: 4}\right)$, were also detected. The $\mathrm{G}+\mathrm{C}$ content of the genomic DNA of strains SIR-1 ${ }^{\top}$ and SHI-1 was between $69 \cdot 3$ and $70.0 \mathrm{~mol} \%$ (as determined by HPLC). Strains SIR-1 ${ }^{\top}$ and SHI-1 shared almost identical $16 \mathrm{~S}$ rDNA sequences, and clustered with the genus Nannocystis as their closest relative upon phylogenetic analysis. However, the phylogenetic distance between the novel strains and the genus Nannocystis was large enough to warrant their different generic allocation. This finding was supported by significant phenotypic differences between the novel strains and Nannocystis. Thus, strains SIR-1 ${ }^{\top}$ and SHI-1 represent a novel genus and species, for which the names Plesiocystis and Plesiocystis pacifica, respectively, are proposed. The type strain of the species is SIR $-1^{\top}\left(=\mathrm{JCM} 11591^{\top}=\mathrm{DSM} 14875^{\top}\right.$ $=$ AJ $13960^{\top}$ ).
\end{abstract}

\section{INTRODUCTION}

The myxobacteria are Gram-negative, rod-shaped, gliding bacteria with a high $\mathrm{G}+\mathrm{C}$ content. One unique characteristic of myxobacteria is a process of intercellular development that leads to fruiting-body formation. Morphological features of fruiting bodies have been regarded as a key criterion for the classification of this group of bacteria (McCurdy, 1989; Reichenbach, 1993). 16S rDNA sequence studies have revealed that they form a relatively homogeneous cluster within the $\delta$-Proteobacteria (Shimkets \& Woese, 1992; Spröer et al., 1999).

Published online ahead of print on 28 June 2002 as DOI 10.1099/ijs.0.02418-0.

Abbreviation: PUFA, polyunsaturated fatty acid.

The DDBJ accession numbers for the $16 \mathrm{~S}$ rRNA gene sequences of strains SIR-1 ${ }^{\top}$ and SHI-1 are AB083432 and AB016469, respectively.

The fatty acid profiles of strains SIR $-1^{\top}$ and SHI-1 can be found as supplementary data in IJSEM Online (http://isj.sgmjournals.org). Scanning electron micrographs of Plesiocystis pacifica are also available in IJSEM Online. 
Myxobacteria have long been regarded as soil bacteria (Dawid, 2000), and only a few investigators have reported the isolation of myxobacteria from marine environments (Roper \& Marshall, 1977; Yamamoto et al., 1982). However, because of insufficient physiological and taxonomic descriptions, evidence as to the existence of 'true' marine myxobacteria has remained obscure. Previously, we have reported the isolation and characterization of marine myxobacteria, i.e. strains SHI- $1, \mathrm{SMP}-2^{\mathrm{T}}$ and SMP $-10^{\mathrm{T}}$, from Japanese coastal saline environments. These novel strains are positioned in the myxobacterial clade based on phylogenetic analyses, but are very distantly related to any recognized species. Strains SMP- ${ }^{\mathrm{T}}$ and SMP- $10^{\mathrm{T}}$, which form yellow-coloured fruiting bodies, have recently been described as members of a newly created genus, Haliangium, as Haliangium ochraceum and Haliangium tepidum, respectively (Fudou et al., 2002). Strain SHI-1 is only distantly related to members of the genus Haliangium (based on $16 \mathrm{~S}$ rDNA phylogenetic analyses), and is more closely related to the genus Nannocystis. Because of its scant fruiting-body formation, a clear taxonomic affiliation based on morphological features was hampered in the case of strain SHI-1.

Recently, we have isolated an additional marine strain, SIR$1^{\mathrm{T}}$, which has morphological features similar to those of strain SHI-1, but this strain produces ample fruiting bodies. Therefore, in this study, we investigated the taxonomic characteristics of the two marine isolates, SIR- $1^{\mathrm{T}}$ and SHI-1, more thoroughly. On the basis of the phylogenetic and chemotaxonomic data generated for the two marine strains, we propose to classify them as representing a novel genus, Plesiocystis, and species, Plesiocystis pacifica.

\section{METHODS}

Bacterial strains. Sample collection, isolation and cultivation of the marine myxobactria were performed as described previously (Iizuka et al., 1998a). Strain SHI-1 was isolated from a sand sample collected in February 1997 at a rocky beach on Hachijo-jima Island, Japan. Strain SIR-1 ${ }^{\mathrm{T}}$ was isolated from a semi-dried sample of sea grass (Zostera sp.) collected in June 1999 at a sandy beach on Iriomote-jima Island, Japan. Strains SIR- $1^{\mathrm{T}}$ and SHI-1 have been deposited in the Japan Collection of Microorganisms (JCM; Saitama, Japan) as JCM $11591^{\mathrm{T}}$ and JCM 11592, respectively, and in the Deutsche Sammlung von Mikroorganismen und Zellkulturen (DSMZ; Braunschweig, Germany) as DSM $14875^{\mathrm{T}}$ and DSM 14876, respectively. The deposition numbers for the Culture Collection of Ajinomoto Co., Inc., were AJ $13960^{\mathrm{T}}$ for strain SIR $1^{\mathrm{T}}$ and AJ 13393 for strain SHI-1. Nannocystis exedens DSM $71^{\mathrm{T}}$, 'Sorangium cellulosum' YA2 (=AJ 13585), Myxococcus xanthus IFO $13542^{\mathrm{T}}$, H. ochraceum SMP-2 ${ }^{\mathrm{T}}\left(=\mathrm{JCM} 11303^{\mathrm{T}}=\mathrm{DSM} 14365^{\mathrm{T}}\right)$ and H. tepidum SMP $-10^{\mathrm{T}}\left(=\mathrm{JCM} 11304^{\mathrm{T}}=\mathrm{DSM} 14436^{\mathrm{T}}\right)$ were used as reference strains.

Media and cultivation. The basal solution for all culture media (SWS) used in this study contained $0.5 \mathrm{mg}$ cyanocobalamine $1^{-1}$ and $20 \mathrm{~g} \mathrm{NaCl}^{-1}$. The SWS in this study had the same composition as reported previously (Iizuka et al., 1998a), except that the concentration of iron(III) citrate was reduced to $10 \mathrm{mg} \mathrm{l}^{-1}$. The $\mathrm{pH}$ of the media was adjusted to $7 \cdot 4$ with $1 \mathrm{M} \mathrm{NaOH}$. Vy2/SWS agar [5.0 g baker's yeast paste $1^{-1} ; 15 \mathrm{~g}$ Bacto agar (Difco) $\left.1^{-1}\right]$ was used for routine cultivation of the marine isolates. The yeast paste was prepared from dried yeast (Wako), after washing three times in deionized water. One-third strength (1/3) CY/SWS agar $\left[1 \cdot 0 \mathrm{~g}\right.$ Bacto Casitone (Difco) $1^{-1} ; 0 \cdot 3 \mathrm{~g}$ Bacto yeast extract (Difco) $l^{-1}$; $15 \mathrm{~g}_{\text {agar }} \mathrm{l}^{-1}$ ] was used for colony observation. Incubation was at $28^{\circ} \mathrm{C}$ unless otherwise noted. To obtain cell mass for chemotaxonomic analyses, strain SHI-1 was grown in 1/3 CY/SWS liquid medium. For strain SIR-1 ${ }^{\mathrm{T}}$, casein/SWS liquid medium (SWS with $2 \mathrm{~g}$ casein sodium $1^{-1}$; Tokyo Kasei) was used, because the strain showed limited growth in $1 / 3 \mathrm{CY} / \mathrm{SWS}$ liquid medium. The media were inoculated with agar pieces cut off from the edges of swarms on Vy2/SWS agar, and incubated on a rotary shaker at 120 r.p.m. at $28^{\circ} \mathrm{C}$ in $500 \mathrm{ml}$ Erlenmeyer flasks each containing $100 \mathrm{ml}$ medium.

Morphological observations. Colonies and fruiting bodies were observed under a dissecting microscope. General cell morphology was studied using a Nikon OPTIPHOT phase-contrast microscope. Specimens of fruiting bodies used for scanning electron microscopy were fixed for $3 \mathrm{~h}$ in osmium(VIII)-oxide (Nacalai) vapour. Fixed specimens were freeze-dried, then sputter-coated with platinum/ palladium and viewed in a Hitachi FE-SEM (S-4000) scanning electron microscope.

Biochemical tests. Oxidase activity was determined with oxidase test paper strips (Wako). Catalase was detected with $3 \%(\mathrm{w} / \mathrm{v})$ $\mathrm{H}_{2} \mathrm{O}_{2}$. Anaerobic growth was checked with the AnaeroPack system (Mitsubishi gas chemical). SWS agar ( $10 \cdot 0 \mathrm{~g}$ Bacto agar $1^{-1}$ in SWS) was used as basal medium for the following tests: gelatinase; cellulase; chitinase; Tween 80 esterase; alginase. Gelatinase was checked for using the disappearance of precipitate by dropping $30 \%(\mathrm{w} / \mathrm{v})$ trichloroacetic acid on SWS agar supplemented with $4 \mathrm{~g}$ Bacto gelatin $1^{-1}$ (Difco). Cellulase was checked for by decomposition of filter paper on SWS agar with $2 \mathrm{~g} \mathrm{NaNO}_{3} \mathrm{l}^{-1}$. Overlay medium was prepared by pouring an upper layer of medium on $1 / 3$ CY/SWS agar. Chitinase was detected from a hydrolytic zone on chitin overlay medium [top agar: SWS agar with $4 \mathrm{~g}$ purified chitin $1^{-1}$ (Sigma)]. Alginase activity was determined from the disappearance of precipitate by dropping acetone on alginate overlay medium (top agar: $25 \mathrm{~g}$ sodium alginate $1^{-1}$ and $12 \mathrm{~g}$ Bacto agar $\mathrm{l}^{-1}$ in deionized water; Sakata \& Yoshikawa, 2000). Tween 80 esterase was detected in Tween 80 medium by monitoring precipitate formation $(1 / 3$ CY/SWS agar with $1 \mathrm{~g}$ Tween $80 \mathrm{l}^{-1}$ ). Amylase was detected on starch medium $\left(1 / 3 \mathrm{CY} / \mathrm{SWS}\right.$ agar with $2 \mathrm{~g}$ soluble starch $\left.\mathrm{l}^{-1}\right)$ by means of the iodine-starch reaction. DNase was checked for by means of the disappearance of precipitate with $1.5 \mathrm{M} \mathrm{HCl}$ in DNA medium [1/3 CY/SWS agar with $4 \mathrm{~g}$ DNA $1^{-1}$ (Nacalai)]. Caseinase was checked for by means of the lysis of precipitate in casein/SWS liquid medium. To detect bacteriolytic activities, streaks of livebacterium cell paste [Escherichia coli W3110 (ATCC 27325), Pseudoalteromonas haloplanktis ATCC $14393^{\mathrm{T}}$ ] smeared on SWS agar were inoculated with small pieces of agar blocks of myxobacterial cultures at the ends. Decomposition of autoclaved yeast cells was checked by the formation of lytic zones around or inside the colonies on $\mathrm{Vy} 2 / \mathrm{SWS}$ agar plates. In all the above cases, incubations were done at $28^{\circ} \mathrm{C}$ for $10-14$ days. An API ZYM system (bioMérieux) was also used to detect the other enzymic activities, according to the manufacturer's directions, with the following modification. For marine isolates, sterile SWS was used instead of distilled water to prepare the reaction mixture. Agar blocks (approx. $3 \mathrm{~mm}^{3}$ ) cut from colonies on Vy2/SWS agar were used as inocula and then incubated for $6 \mathrm{~h}$ at $37^{\circ} \mathrm{C}$.

Growth responses to temperature, salt concentration and pH. To check growth responses to temperature, cultures on Vy2/SWS agar were incubated at $8-40{ }^{\circ} \mathrm{C}$, after a 5 day pre-culture at $25^{\circ} \mathrm{C}$. The effect of $\mathrm{NaCl}$ on growth was studied with $\mathrm{Vy} 2 / \mathrm{SWS}$ agar and casein/SWS liquid media with $\mathrm{NaCl}$ concentrations ranging from 1.0 to $60 \mathrm{~g} \mathrm{l}^{-1}$. The specific requirement for $\mathrm{NaCl}$ and the cation and anion requirements were determined on modified 
1/3 CY/SWS agar according to the methods of Bouchotroch et al. (2001). To determine the $\mathrm{pH}$ range for growth, cultivation at different $\mathrm{pH}$ values was performed on $1 / 3 \mathrm{CY} / \mathrm{SWS}$ agar buffered with $5 \mathrm{mM}$ MES (pH 5.2-6.7), $5 \mathrm{mM}$ TES (pH 6.5-8.5) and $5 \mathrm{mM}$ 3-[(1,1-dimethyl-2-hydroxyethyl)amino]-2-hydroxypropanesulfonic acid (AMPSO, pH 8.0-9.7). All of the buffering reagents were obtained from Sigma.

Chemotaxonomy. Respiratory quinones were extracted with acetone, fractionated by silica-gel TLC and analysed by HPLC (Hiraishi et al., 1984). The molecular masses of quinones was determined by MS using a JEOL-JMS-DX300 (EI-MS) spectrometer. Cellular fatty acid composition was determined by extracting the fatty acids as their methyl esters and analysing the extract with GLC and GC-MS (Fudou et al., 2002). The molecular mass of the long-chain polyunsaturated fatty acid (PUFA) $\left(\mathrm{C}_{20: 4}\right)$ was measured by GC-MS.

DNA base content. DNA was extracted in TE buffer with lysozyme (Saito \& Miura, 1963), then purified using a Qiagen DNA purification kit according to the manufacturer's instructions. The $\mathrm{G}+\mathrm{C}$ content $(\mathrm{mol} \%)$ of genomic DNA was determined by reversed-phase HPLC (Mesbah et al., 1989).

165 rDNA sequencing and phylogenetic analyses. $16 \mathrm{~S}$ rDNA fragments from the crude lysate (Hiraishi, 1992) were amplified by PCR with a universal set of primers (Lane, 1991). PCR products were sequenced with a SequiTherm cycle sequencing kit (Epicentre Technologies); this was followed by detection with a Pharmacia laser fluorescent DNA sequencer (Iizuka et al., 1998b). The sequences determined were compared with those retrieved from the DDBJ/ EMBL/GenBank nucleotide sequence databases. A distance matrix tree was constructed by the neighbour-joining method (Saitou \& Nei, 1987), and the topology of the phylogenetic tree was built by bootstrap analysis (Felsenstein, 1985), using the CLUSTAL $\mathrm{W}$ program (Thompson et al., 1994). The $16 \mathrm{~S}$ rDNA sequences of strains SIR-1 ${ }^{\mathrm{T}}$ and SHI-1 were deposited in the DDBJ under accession numbers $\mathrm{AB} 083432$ and $\mathrm{AB} 016469$, respectively.

\section{RESULTS AND DISCUSSION}

\section{Morphological and cultural characteristics}

The vegetative cells of strains SIR- ${ }^{\mathrm{T}}$ and SHI-1 were rodshaped with blunt, rounded ends (Fig. 1a), and were $0 \cdot 5-0 \cdot 8 \mu \mathrm{m}$ wide and $1 \cdot 5-7 \cdot 0 \mu \mathrm{m}$ long. Both strains showed gliding motility, and spreading colonies (so-called swarms) appeared on the surfaces of agar media. Radial patterns were sometimes formed in the swarms. The agar surface in the swarm area was often shallowly etched and cloudy in appearance. The colour of colonies on 1/3 CY/ SWS agar was pink to white-orange, but pigmentation was not observed on yeast agar. The cell pellets harvested from
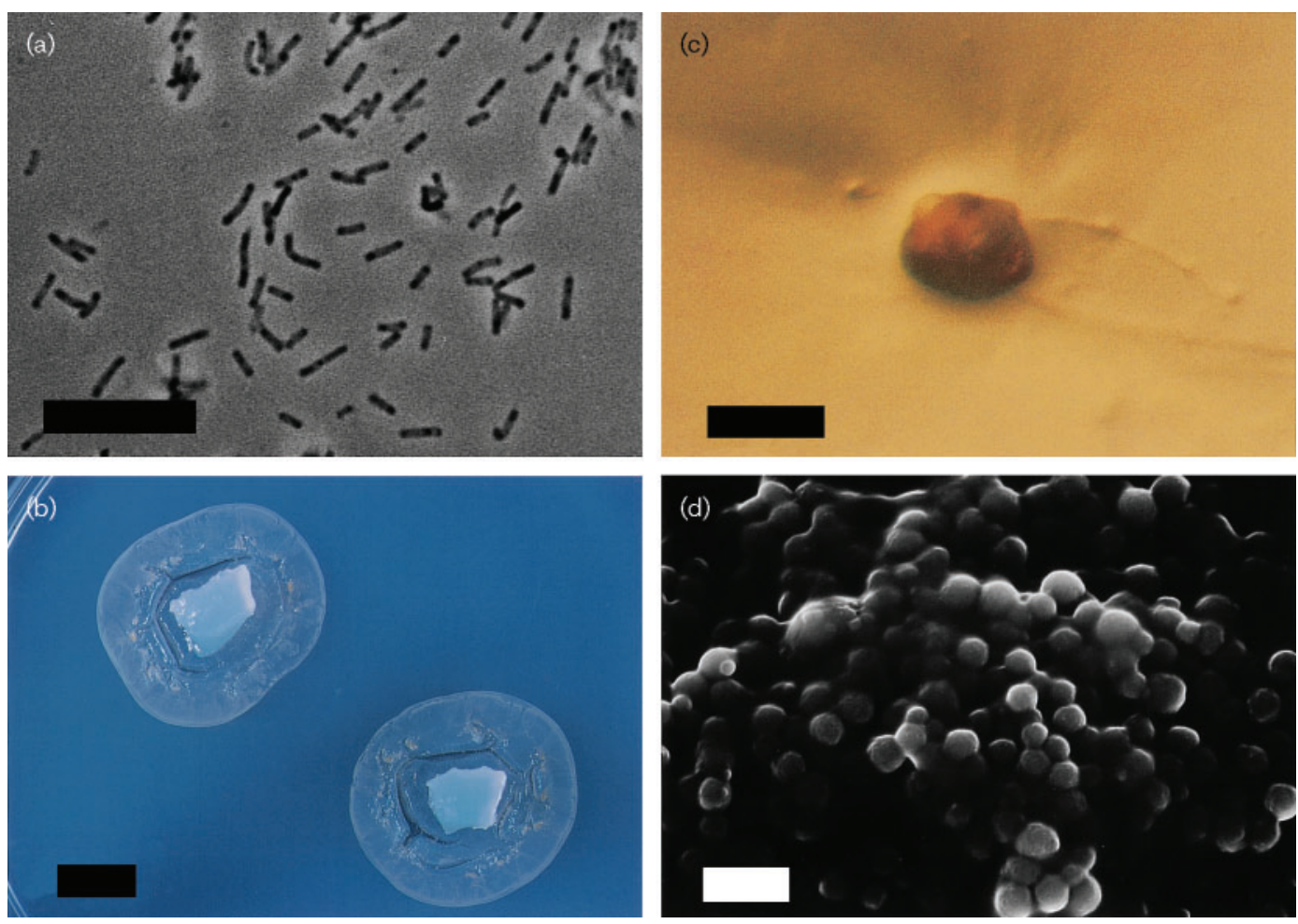

Fig. 1. Photographs showing the morphology of strain SIR-1 $1^{\top}$. (a) Phase-contrast micrograph of vegetative cells cultured in casein/SWS liquid medium for 3 days at $28^{\circ} \mathrm{C}$, observed under oil immersion. Bar, $10 \mu \mathrm{m}$. (b) Swarming colonies formed around inoculated agar blocks on $1 / 3 \mathrm{CY} / \mathrm{SWS}$ agar cultivated for 5 days at $28^{\circ} \mathrm{C}$. The agar gel within the swarms was cleaved but not liquefied. Bar, $1.0 \mathrm{~cm}$. (c) Solitary fruiting body on the surface of Vy2/SWS agar after 10-14 days cultivation at $28^{\circ} \mathrm{C}$, observed under a dissecting microscope. Bar, $100 \mu \mathrm{m}$. (d) Scanning electron micrograph of the spherical myxospores. A fruiting body on Vy2/SWS agar was removed onto a small filter-paper strip and crushed with a needle tip. Bar, $1 \cdot 0 \mu \mathrm{m}$. 
liquid cultures were pinkish-orange to orange in colour. The cells tended to concentrate at the swarm periphery, forming a dense band. The agar gel within the swarms was often cleaved, especially in 1/3 CY/SWS agar (Fig. 1b), but not liquefied. Spherical or oval-shaped cell clusters that migrated away from the centre and left etched paths in the agar surface were observed on Vy2/SWS agar. The clusters transformed into fruiting bodies after 1-2 weeks cultivation. Strain SIR $-1^{\mathrm{T}}$ reproducibly formed globular to polyhedral fruiting bodies, of $100-500 \mu \mathrm{m}$ in diameter, on the surface of Vy2/SWS agar after 1-2 weeks incubation (Fig. 1c). While strain SHI-1 also formed those structures, the frequency of formation was considerably lower than that of strain SIR- $1^{\mathrm{T}}$. The fruiting bodies were sessile and composed of slime and spherical myxospores. They were scattered on the agar surface, and a large number of them were sunk into the agar gel in self-made holes. Neither an outer envelope nor a wall-like structure was observed by light or electron microscopy. The colour of the fruiting bodies ranged from pinkish-orange to brownish-orange. When the fruiting bodies were crushed, many spherical cells, of $0 \cdot 5-0 \cdot 7 \mu \mathrm{m}$ in diameter, were observed with electron microscopy (Fig. 1d). The colony appearances and vegetative cell shapes coincided well with those of myxobacteria belonging to the suborder Sorangineae. Although the fruiting bodies of strain SIR-1 ${ }^{\mathrm{T}}$ lacked a firm wall, the spherical myxospores within them especially resembled those of the genus Nannocystis (Reichenbach, 1970). In liquid cultures, strains SIR-1 ${ }^{\mathrm{T}}$ and SHI-1 formed cell clumps and showed no dispersed growth, as is often the case with myxobacteria.

\section{Physiological characteristics}

The phenotypic features of the marine isolates, along with the reference terrestrial strain N. exedens DSM $71^{\mathrm{T}}$, are listed

Table 1. Phenotypic characteristics that differentiate strain $S I R-1^{\top}$ from related strains of myxobacteria

+ , Positive; -, negative; W, weakly positive; ND, not determined.

\begin{tabular}{|c|c|c|c|c|}
\hline Characteristic & Strain SIR-1 ${ }^{\mathrm{T}}$ & H. ochraceum & H. tepidum & N. exedens \\
\hline Colony colour (Vy2) & Colourless & Brownish-yellow & Whitish-yellow & Light-pink to colourless \\
\hline \multicolumn{5}{|l|}{ Rod cell: } \\
\hline Length $(\mu \mathrm{m})$ & $1 \cdot 5-7 \cdot 0$ & $3 \cdot 0-8 \cdot 0$ & $3 \cdot 0-8 \cdot 0$ & $1 \cdot 5-5 \cdot 0^{\star}$ \\
\hline \multicolumn{5}{|l|}{ Myxospore: } \\
\hline \multicolumn{5}{|l|}{ Growth at: } \\
\hline $15^{\circ} \mathrm{C}$ & + & - & - & - \\
\hline $18^{\circ} \mathrm{C}$ & + & + & - & $\mathrm{W}$ \\
\hline $37^{\circ} \mathrm{C}$ & - & + & + & + \\
\hline $40^{\circ} \mathrm{C}$ & - & $\mathrm{W}$ & + & + \\
\hline Cation requirement(s) & $\mathrm{Ca}^{2+}, \mathrm{Mg}^{2+}, \mathrm{K}^{+}$ & $\mathrm{Ca}^{2+}, \mathrm{Mg}^{2+}$ & $\mathrm{Ca}^{2+}$ & ND \\
\hline Oxidase & + & $\mathrm{W}$ & $\mathrm{W}$ & $+^{*}$ \\
\hline Catalase & $\mathrm{w} /-$ & + & - & $+^{*}$ \\
\hline \multicolumn{5}{|l|}{ Hydrolysis of: } \\
\hline Starch & - & + & + & - \\
\hline Chitin & - & $\mathrm{W}$ & - & - \\
\hline DNA & $\mathrm{W}$ & + & + & - \\
\hline Tween 80 & $\mathrm{w} /-$ & + & + & $\mathrm{W}$ \\
\hline \multicolumn{5}{|l|}{ API ZYM test: } \\
\hline$\alpha$-Glucosidase & - & - & + & - \\
\hline$\beta$-Glucosidase & - & $\mathrm{W}$ & + & - \\
\hline
\end{tabular}

${ }^{\star}$ Data were obtained from Reichenbach (1989). 
in Table 1. Strains SIR-1 $1^{\mathrm{T}}$ and SHI-1 were strictly aerobic chemo-organotrophs that used oxygen as the terminal electron acceptor. Both strains decomposed live Gramnegative bacterial cells. Lytic action on autoclaved yeast cells was not observed. The API ZYM activity profiles of both strains were identical and differed little from that of N. exedens DSM $71^{\mathrm{T}}$. Strains SIR- $1^{\mathrm{T}}$ and SHI-1 demonstrated the presence of alkaline phosphatase, acid phosphatase and naphthol-AS-BI-phosphohydrolase. Esterase $\left(\mathrm{C}_{4}\right.$ and $\left.\mathrm{C}_{8}\right)$, lipase $\left(\mathrm{C}_{4}\right)$, leucine arylamidase, valine arylamidase, cystine arylamidase, trypsin, chymotrypsin, galactosidase ( $\alpha$ - and $\beta$-), $\beta$-glucuronidase, glucosidase ( $\alpha$ and $\beta$-), $N$-acetyl- $\beta$-glucosaminidase, $\alpha$-mannosidase and $\alpha$-fucosidase activities were not detected. With both strains, growth occurred at temperatures between 15 and $32{ }^{\circ} \mathrm{C}$, with an optimum around $28-30^{\circ} \mathrm{C}$. No growth occurred above $34^{\circ} \mathrm{C}$ or below $10^{\circ} \mathrm{C}$. The optimum $\mathrm{pH}$ range for growth was $7 \cdot 5-8 \cdot 5$. No growth occurred below $\mathrm{pH} 5 \cdot 5$ or above $\mathrm{pH} 9 \cdot 5$.

Marine bacteria have been defined as those that inhabit marine environments and require sodium for growth. Magnesium is also often needed for growth (MacLeod, 1965). To demonstrate the marine nature of strain SIR- $1^{\mathrm{T}}$, it was tested for cation requirements for growth. Strain SIR $-1^{\mathrm{T}}$ showed no growth in the absence of sodium. Growth occurred in the presence of $1 \cdot 0-4 \cdot 0 \%(\mathrm{w} / \mathrm{v}) \mathrm{NaCl}$, with an optimum concentration around $2 \cdot 0-3 \cdot 0 \%(\mathrm{w} / \mathrm{v})$. None of the other cations tested $\left(\mathrm{Mg}^{2+}, \mathrm{Ca}^{2+}, \mathrm{K}^{+}\right.$and $\left.\mathrm{Li}^{+}\right)$ compensated for the $\mathrm{Na}^{+}$requirement. Besides $\mathrm{Na}^{+}$, strain SIR-1 ${ }^{\mathrm{T}}$ required $\mathrm{Ca}^{2+}, \mathrm{Mg}^{2+}$ and $\mathrm{K}^{+}$, and growth was markedly reduced when any of these three cations was omitted from the medium. A previous study has shown that strain SHI-1 also requires the cations noted above, while the growth of terrestrial myxobacteria is inhibited by the addition of $\mathrm{NaCl}$ (Iizuka et al., 1998a). As for the anion requirement, $\mathrm{NaBr}$ could replace $\mathrm{NaCl}$ in the case of both isolates, although the growth rate was slower; however, $\mathrm{NaI}$ could not replace $\mathrm{NaCl}$. Strains SIR-1 $1^{\mathrm{T}}$ and SHI-1 had the properties of marine bacteria. According to Kushner's definition, the two strains fall into the category of slightly halophilic bacteria (Kushner, 1978). From these characteristics, it was inferred that strains SIR- $1^{\mathrm{T}}$ and SHI- 1 were specifically adapted to marine environments.

Both strains were oxidase-positive and catalase-variable (weakly positive or negative). Casein, gelatin and DNA (weak reaction) were hydrolysed by both strains, but starch, chitin, alginate and cellulose were not. Tween 80 was weakly hydrolysed or not hydrolysed by both strains.

\section{Chemotaxonomy}

The major respiratory quinone of myxobacteria, including that of the recently described genus of marine myxobacteria Haliangium, has been reported to be MK-8 (Fudou et al., 2002). Although the major quinone of strain SHI-1 was reported to be MK-8 in a previous study (Iizuka et al., 1998a), it was corrected to MK-8 $\left(\mathrm{H}_{2}\right)$ in this study with the aid of the MS analysis. Strain SIR $-1^{\mathrm{T}}$ also produced MK-8 $\left(\mathrm{H}_{2}\right)$. No ubiquinone was detected in either strain. The distribution of partially saturated menaquinones is almost confined to Gram-positive bacteria with a high $\mathrm{G}+\mathrm{C}$ content (i.e. those belonging to the Actinobacteria) (Collins, 1992; Hiraishi, 1999). Therefore, the presence of MK- $8\left(\mathrm{H}_{2}\right)$ in strains SIR $-1^{\mathrm{T}}$ and SHI- 1 is unusual, especially as they are myxobacteria. Among the Gram-negative bacteria, some species of sulfate-reducing $\delta$-Proteobacteria are known to produce partially saturated menaquinones (Collins \& Widdel, 1986).

Strains SIR $-1^{\mathrm{T}}$ and SHI-1 possessed similar fatty acid profiles, with iso- $\mathrm{C}_{15: 0}(32 \cdot 3-35 \cdot 6 \%$ of total fatty acids) and iso- $\mathrm{C}_{16: 0}(13 \cdot 5-14 \cdot 6 \%)$ as the major components, in accord with those of known species of myxobacteria (Yamanaka et al., 1988). A long-chain PUFA $\left(\mathrm{C}_{20: 4}\right)$ was also detected in substantial amounts $(14 \cdot 1-17 \cdot 5 \%)$. anteiso$\mathrm{C}_{16: 0}(0 \cdot 3-1 \cdot 0 \%)$ and anteiso- $\mathrm{C}_{17: 0}(0 \cdot 9-1 \cdot 2 \%)$, but not hydroxy acids, were detected. The anteiso-branched acids have been reported to be present in the marine species H. ochraceum and H. tepidum as a chemotaxonomic marker of the marine myxobacteria (Fudou et al., 2002). This assumption was confirmed by the presence of this marker in the novel marine strains described here. The presence of a long-chained PUFA $\left(\mathrm{C}_{20: 4}\right)$ was a characteristic of the two strains, and has not been reported for any known myxobacteria. PUFAs are present in marine psychrophilic bacteria of the genus Shewanella, and may function to modify the fluidity and stability of cellular membranes at low temperatures (Russell \& Nichols, 1999). The role of PUFAs in strains SIR- $1^{\mathrm{T}}$ and SHI- 1 remains unclear, as they are mesophilic bacteria that do not grow below $10^{\circ} \mathrm{C}$. The chemotaxonomic characteristics of strains SIR- $1^{\mathrm{T}}$ and SHI-1, noted above, strongly suggest that they represent a novel taxon of the myxobacteria. The fatty acid profiles of strains SIR- $1^{\mathrm{T}}$ and SHI-1 can be found as supplementary data in IJSEM Online (http://ijs.sgmjournals.org).

\section{DNA base content}

The genomic DNA G $+\mathrm{C}$ contents of strains SIR $-1^{\mathrm{T}}$ and SHI-1 were $69 \cdot 3$ and $70 \cdot 0 \mathrm{~mol} \%$, respectively. These values are within the range reported for other myxobacteria, which is between 67 and $72 \mathrm{~mol} \%$ (Reichenbach \& Dworkin, 1992).

\section{Phylogenetic analysis}

Strains SIR- ${ }^{\mathrm{T}}$ and SHI- 1 were subjected to phylogenetic analyses based on almost-complete $16 \mathrm{~S}$ rDNA sequences. The sequence similarity between the two strains was $99.5 \%$, suggesting that they should be classified as a single species or as very closely related species. The above-mentioned phenotypic and chemotaxonomic resemblance of the two strains also supports this notion. The dendrogram constructed on the basis of the $16 \mathrm{~S}$ rDNA sequence data of the two marine isolates and other representative myxobacterial species is shown in Fig. 2. Strains SIR-1 ${ }^{\mathrm{T}}$ and SHI-1 form a 


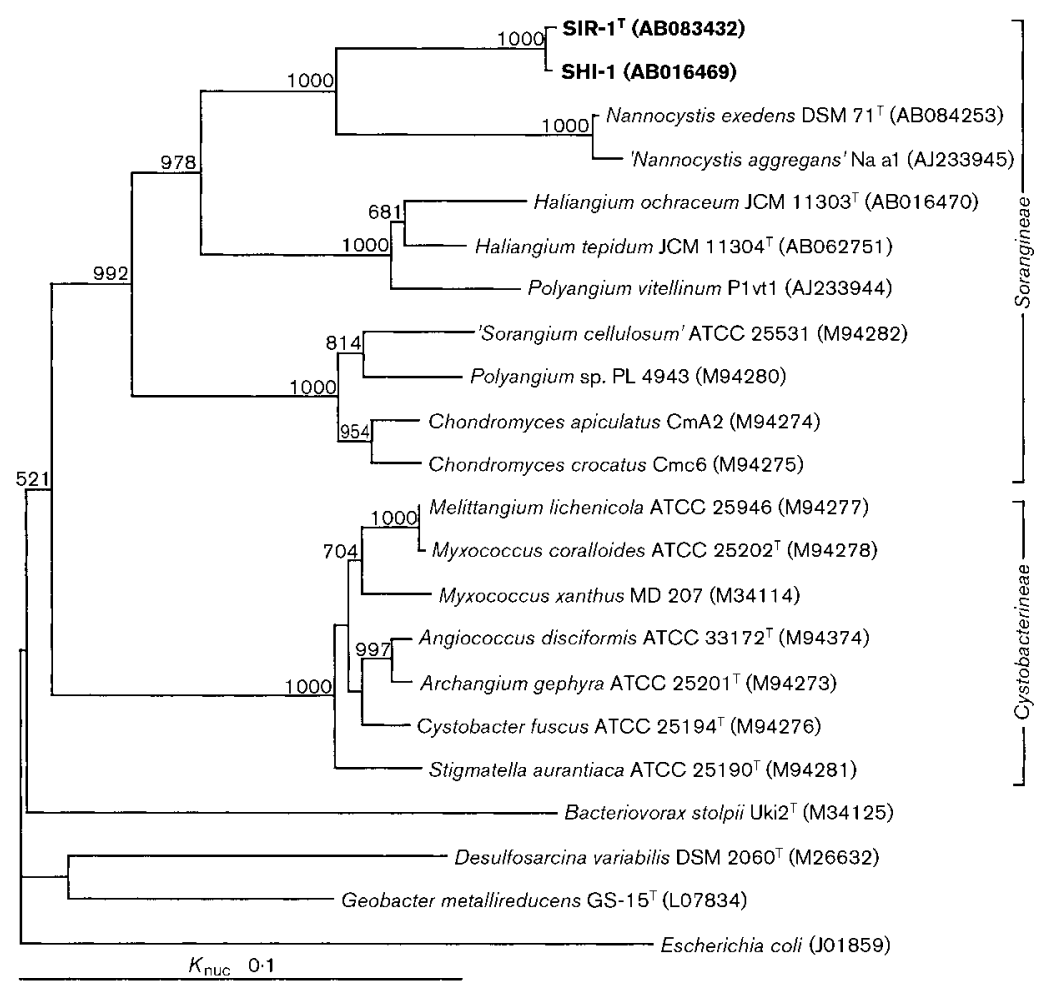

Fig. 2. Phylogenetic dendrogram of the myxobacteria, based on 16S rDNA sequences. Bar, 10 nt substitutions per 100 sites. The numbers at branch points indicate the level of bootstrap support, based on 1000 resamplings. Only values greater than 600 are shown.

distinct cluster that falls within the suborder Sorangineae, with $N$. exedens as their closest relative. This is in accordance with the morphological similarities mentioned above. However, the levels of sequence similarity between our isolates and $N$. exedens are $89 \cdot 3-89 \cdot 4 \%$, which are low enough to warrant different generic allocations. The other marine myxobacteria, $H$. ochraceum and $H$. tepidum, are even more widely separated from strains SIR $-1^{\mathrm{T}}$ and SHI-1, showing only $84 \cdot 4-84 \cdot 5 \% 16 \mathrm{~S}$ rDNA sequence similarity.

In view of their distinct phylogenetic positions, together with their unique cellular components [such as MK- $8\left(\mathrm{H}_{2}\right)$ and PUFA $\left.\left(\mathrm{C}_{20: 4}\right)\right]$ and their habitats, it is logical to conclude that strains SIR $-1^{\mathrm{T}}$ and SHI- 1 should be classified as representatives of a novel genus of myxobacteria. Thus, we propose the creation of the novel genus Plesiocystis, and propose the name Plesiocystis pacifica for the species represented by the two marine isolates described here.

\section{Description of Plesiocystis gen. nov.}

Plesiocystis [Ples.i.o.cys'tis. Gr. masc. n. plesion neighbour; Gr. fem. n. cystis bladder; N.L. fem. n. Plesiocystis neighbour bladder (to imply the genus is phylogenetically clustered next to the genus Nannocystis on the dendrogram)].

Cells are straight rods with blunt, rounded ends ('Sorangium' type). Gram-negative. Spherical myxospores with diameters of $0.5-0.7 \mu \mathrm{m}$ are formed. Vegetative cells move by gliding on solid surfaces, tending to concentrate at the swarm periphery; the agar gel within the swarms is often cleaved. Spherical or oval-shaped cell clusters that migrate away from the centre and leave etched paths in the gel surface are observed on agar media. Fruiting bodies are pinkish- to brownish-orange. They are solitary aggregates, without a distinct wall. Strictly aerobic chemoorganotrophs. Mesophilic, neutrophilic and slightly halophilic. Oxidase-positive and weakly catalase-positive or negative. Casein and gelatin are hydrolysed, whereas starch, chitin, alginate and cellulose are not. Agar gel is not liquefied. Tween 80 is weakly hydrolysed or not hydrolysed. DNA is weakly hydrolysed. The major quinone is MK$8\left(\mathrm{H}_{2}\right)$. The major cellular fatty acid components are iso$\mathrm{C}_{15: 0}$ and iso- $\mathrm{C}_{16: 0}$. anteiso- $\mathrm{C}_{16: 0}$ and anteiso- $\mathrm{C}_{17: 0}$ and a long-chain PUFA $\left(\mathrm{C}_{20: 4}\right)$ are also detected. Hydroxy fatty acids are not detected. The $\mathrm{G}+\mathrm{C}$ content of genomic DNA is nearly $70 \mathrm{~mol} \%$. The phylogenetic position is in the suborder Sorangineae, order Myxococcales. The type species is Plesiocystis pacifica.

\section{Description of Plesiocystis pacifica sp. nov.}

Plesiocystis pacifica (pa.cif'ic.a. N.L. fem. adj. pacifica pertaining to the Pacific Ocean).

Has all the characteristics of the genus. Colonies are coloured light-pink to orange on $1 / 3 \mathrm{CY} / \mathrm{SWS}$ medium. Growth temperature is between 15 and $32^{\circ} \mathrm{C}$. No growth occurs above $34^{\circ} \mathrm{C}$ or below $10^{\circ} \mathrm{C}$. Growth occurs at an $\mathrm{NaCl}$ concentration between 1.0 and $4.0 \%(\mathrm{w} / \mathrm{v})$, with an optimum at $2 \cdot 0-3 \cdot 0 \%(\mathrm{w} / \mathrm{v})$. The $\mathrm{Na}^{+}$requirement cannot be substituted by $\mathrm{Ca}^{2+}, \mathrm{Mg}^{2+}, \mathrm{K}^{+}$or $\mathrm{Li}^{+} . \mathrm{NaBr}$ can partially replace $\mathrm{NaCl}$, but $\mathrm{NaI}$ cannot. Besides $\mathrm{NaCl}$, cations of sea water $\left(\mathrm{Ca}^{2+}, \mathrm{Mg}^{2+}\right.$ and $\left.\mathrm{K}^{+}\right)$are also required. The $\mathrm{pH}$ range for growth is $5 \cdot 5-9 \cdot 0$, with the optimum at neutral $\mathrm{pH}(7 \cdot 0-8 \cdot 5)$. Acid phosphatase, alkaline phosphatase 
and naphthol-AS-BI-phosphohydrolase are detected using the API ZYM system. Esterases and glucosidases are not produced. Autoclaved yeast cells are not decomposed in Vy2/SWS agar. Isolated from the Pacific coasts of Japan. The type strain is SIR $-1^{\mathrm{T}}\left(=\mathrm{JCM} 11591^{\mathrm{T}}=\mathrm{DSM}\right.$ $14875^{\mathrm{T}}=$ AJ $\left.13960^{\mathrm{T}}\right)$.

\section{ACKNOWLEDGEMENTS}

We are grateful to Reiko Yuji and Naoko Kageyama of the Basic Analytical Chemistry Group, Institute of Life Sciences, Ajinomoto Co., Inc., for MS and GC-MS measurements. The samples from Iriomote-jima Island were kindly provided by Takayuki Kajiura of Pharmaceutical Research Laboratories, Ajinomoto Co., Inc.

\section{REFERENCES}

Bouchotroch, S., Quesada, E., del Moral, A., Llamas, I. \& Béjar, V. (2001). Halomonas maura sp. nov., a novel moderately halophilic, exopolysaccharide-producing bacterium. Int J Syst Evol Microbiol 51, 1625-1632.

Collins, M. D. (1992). The genus Brevibacterium. In The Prokaryotes, 2nd edn, pp. 1351-1354. Edited by A. Balows, H. G. Trüper, M. Dworkin, W. Harder \& K.-H. Schleifer. Berlin: Springer-Verlag.

Collins, M. D. \& Widdel, F. (1986). Respiratory quinones of sulphatereducing and sulphur-reducing bacteria: a systematic investigation. Syst Appl Microbiol 8, 8-18.

Dawid, W. (2000). Biology and global distribution of myxobacteria in soils. FEMS Microbiol Rev 24, 403-427.

Felsenstein, J. (1985). Confidence limits on phylogenies: an approach using the bootstrap. Evolution 39, 783-791.

Fudou, R., Jojima, Y., lizuka, T. \& Yamanaka, S. (2002). Haliangium ochraceum gen. nov., sp. nov. and Haliangium tepidum sp. nov. Novel moderately halophilic myxobacteria isolated from coastal saline environments. J Gen Appl Microbiol 48, 109-115.

Hiraishi, A. (1992). Direct automated sequencing of $16 \mathrm{~S}$ rDNA amplified by polymerase chain reaction from bacterial cultures without DNA purification. Lett Appl Microbiol 15, 210-213.

Hiraishi, A. (1999). Isoprenoid quinones as biomarkers of microbial populations in the environment. J Biosci Bioeng 88, 449-460.

Hiraishi, A., Hoshino, Y. \& Kitamura, H. (1984). Isoprenoid quinone composition in the classification of Rhodospirillaceae. J Gen Appl Microbiol 30, 197-210.

lizuka, T., Jojima, Y., Fudou, R. \& Yamanaka, S. (1998a). Isolation of myxobacteria from the marine environment. FEMS Microbiol Lett $169,317-322$.

lizuka, T., Yamanaka, S., Nishiyama, T. \& Hiraishi, A. (1998b). Isolation and phylogenetic analysis of aerobic copiotrophic ultramicrobacteria from urban soil. J Gen Appl Microbiol 44, 75-84.

Kushner, D. J. (1978). Life in high salt and solute concentrations: halophilic bacteria. In Microbial Life in Extreme Environments, pp. 318-346. Edited by D. J. Kushner. New York: Academic Press.

Lane, D. J. (1991). 16S/23S rRNA sequencing. In Nucleic Acid Techniques in Bacterial Systematics, pp. 115-175. Edited by E. Stackebrandt \& M. Goodfellow. Chichester: Wiley.

MacLeod, R. A. (1965). The question of the existence of specific marine bacteria. Bacteriol Rev 29, 9-23.
McCurdy, H. D. (1989). Order Myxococcales Tchan, Pochon and Prevot 1948, 398 (with contributions of E. R. Brockman, H. Reichenbach, and D. White), pp. 2139-2170. In Bergey's Manual of Systematic Bacteriology, vol. 3. Edited by J. T. Staley, M. P. Bryant, N. Pfennig \& J. G. Holt. Baltimore: Williams \& Wilkins.

Mesbah, M., Premachandran, U. \& Whitman, W. B. (1989). Precise measurement of the $\mathrm{G}+\mathrm{C}$ content of deoxyribonucleic acid by high-performance liquid chromatography. Int J Syst Bacteriol 39, 159-167.

Reichenbach, H. (1970). Nannocystis exedens gen. nov., spec. nov., a new myxobacterium of the family Sorangiaceae. Arch Mikrobiol 70, 119-138.

Reichenbach, H. (1989). Genus II. Nannocystis. In Bergey's Manual of Systematic Bacteriology, vol. 3, pp. 2162-2166. Edited by J. T. Staley, M. P. Bryant, N. Pfennig \& J. G. Holt. Baltimore: Williams \& Wilkins.

Reichenbach, H. (1993). Biology of the myxobacteria: ecology and taxonomy. In Myxobacteria II, pp. 16-32. Edited by M. Dworkin \& D. Kaiser. Washington, DC: American Society for Microbiology.

Reichenbach, H. \& Dworkin, M. (1992). The myxobacteria. In The Prokaryotes, 2nd edn, pp. 3416-3487. Edited by A. Balows, H. G. Trüper, M. Dworkin, W. Harder \& K.-H. Schleifer. Berlin: Springer-Verlag.

Roper, M. M. \& Marshall, K. C. (1977). Lysis of Escherichia coli by a marine myxobacter. Microb Ecol 3, 167-171.

Russell, N. J. \& Nichols, D. S. (1999). Polyunsaturated fatty acids in marine bacteria - a dogma rewritten. Microbiology 145, 767-779.

Saito, H. \& Miura, K. (1963). Preparation of transforming deoxyribonucleic acid by phenol treatment. Biochim Biophys Acta 72, 619-629.

Saitou, N. \& Nei, M. (1987). The neighbor-joining method: a new method for reconstructing phylogenetic trees. Mol Biol Evol 4, 406-425.

Sakata, T. \& Yoshikawa, T. (2000). Detection methods for macromolecule decomposing bacteria. In Experimental Methods in Microbiology for Marine Environmental Assessment, p. 100. Edited by Y. Ishida \& H. Sugita. Tokyo: Kosei-sha-Kosei-kaku (in Japanese).

Shimkets, L. \& Woese, C. R. (1992). A phylogenetic analysis of the myxobacteria: basis for their classification. Proc Natl Acad Sci U S A 89, 9459-9463.

Spröer, C., Reichenbach, H. \& Stackebrandt, E. (1999). The correlation between morphological and phylogenetic classification of myxobacteria. Int J Syst Bacteriol 49, 1255-1262.

Thompson, J. D., Higgins, D. G. \& Gibson, T. J. (1994). CLUSTAL W: improving the sensitivity of progressive multiple sequence alignment through sequence weighting, position-specific gap penalties and weight matrix choice. Nucleic Acids Res 22, 4673-4680.

Yamamoto, H., Ezura, Y. \& Kimura, T. (1982). Evaluation of biological agents affecting on the survival of Vibrio parahaemolyticus in seawater. Bull Jpn Soc Sci Fish 48, 1433-1439.

Yamanaka, S., Fudo, R., Kawaguchi, A. \& Komagata, K. (1988). Taxonomic significance of hydroxy fatty acids in myxobacteria with special reference to 2-hydoxy fatty acids in phospholipids. J Gen Appl Microbiol 33, 247-265. 